worts: morts

nime
UCRL --90497

DE84014526

\title{
A High-Bandwidth Multichannel Fiber Opti System for Measuring Gamma Rays
}

\author{
F. Roeske, D. Smith,
}

B. Pruett, and R. Reedy

This paper was prepared for the Preceedinge of the Society of Photo-Optical Inctrumentation Engineers

$$
\text { Anguet 19-24, } 194
$$

Sen Diego, CA

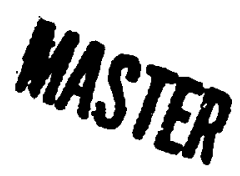

July 1984

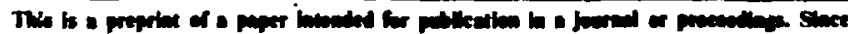

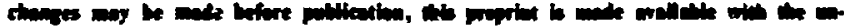

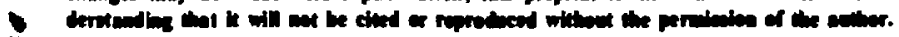




\section{DSCLAMER}

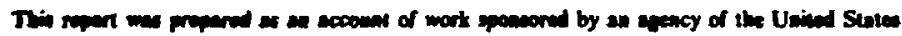

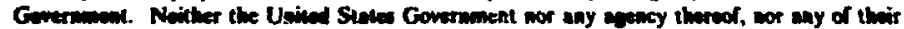

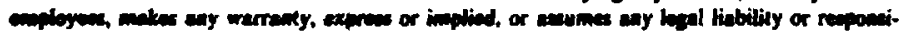

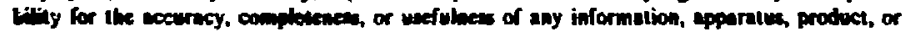

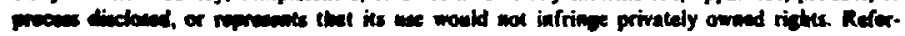

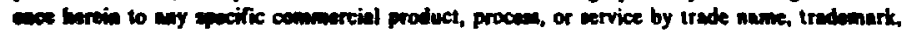

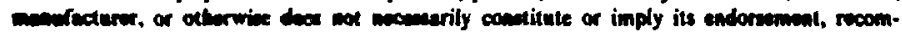

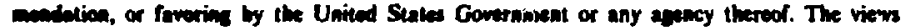

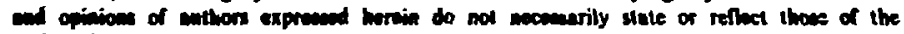
Unind Stave Gowarnment or any areacy thereof. 


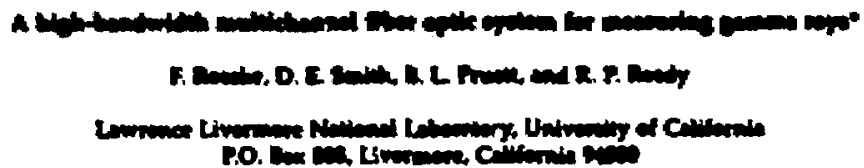

\begin{abstract}
Alimen

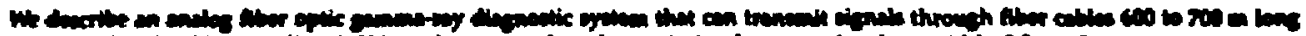

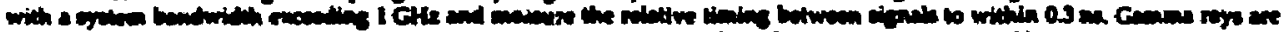

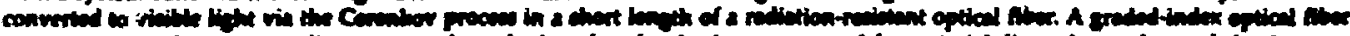

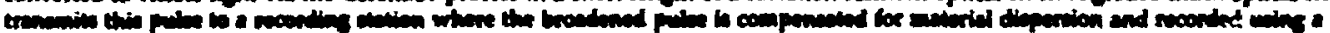

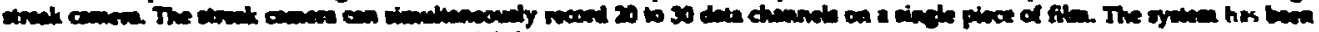

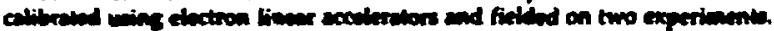

\title{
Introduction
}

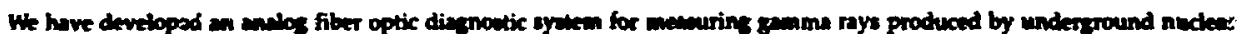

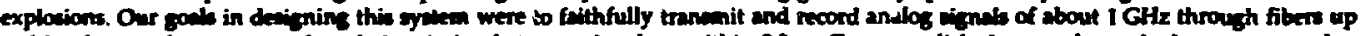

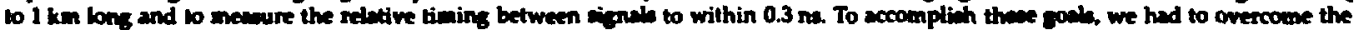
harsh conditions encouniernd during the fielding of a nuclear teat: an intenve radiation envinonuent (which darkens glwa fibers in a nonlinear fachion), phycical difficulties (abraion, strain, and breakage of cables), teraperetures up to $45^{\circ} \mathrm{C}$, and bong tranemiecion didances.

In our syadem, a collimated been of gamma rays impinges on a material that cunverts some of the gamma raye to high-energy

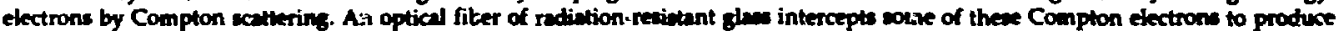
Cerenkor light. The light pube travets through a graded-index optical fiber cable to the ground curface, where it is recorded using a spectral equalizer and a streak camera.

Although the ides of converting gamma radistion to Cerenkov light using an optical fiber placed in the gamma-ray beam has been with us for almod ien years,' optical fiber technokgy has only recently advanced to the point that allows exploitation of this idea to its full potential. To date, several versions of this diagnoatic system have been developed and used on nuclear teats. ${ }^{23}$ These earlier systems recorded the signals wing photomultipliers and high-bandwidth oxilloacopes. Our syntem records the signals using a streak comera.

A fiber optic/streak camera system provides several advantages over a conventional coaxial cable/oacilloacope system:

- The system can transmit and record frequency components up to about $1.5 \mathrm{GHz}$ through a $1-\mathrm{km}$-long fiber. This is important because the gamma-ray signals produced by nuclear explocions may have frequency components greater than $1 \mathrm{GH}$. Furthermore, if the frequency response of the syetem is known, even higher-frequency components can be recovered by uaing mathematical deconvolution. In comparieon, a conventional coaxial cable system using a $1-\mathrm{km}$-long cable is limited to about $400 \mathrm{MHz}$.

- The system can handle multiple channels. Hence, this system can replace ajx high-freed photomultiplier tubes and about 30 oscilloscopes. Such a reduction in recording hardware provides several benefits: the streak, camera requires less spece in the reconding trajler and is eavier to install and maintain. Furthermore, using one fiber-optic detector/recorder system in place of several coaxial cable systems allows more accurate comparison of the relative amplitudes and timing of signals from different channels.

- The system is not susceptible to electromagnetic interference since the dath are transmitted a light pubes rather than electrical pulses. The system is alwo immune to moisture-caused problems that plague coaxial syatems.

In addition, the system is simple, dependable, and able to function in a harh environment. Underground auclear teats are conducted at the bottom of deep hotes (200 to $600 \mathrm{~m}$ deep and 2 to $3 \mathrm{~m}$ in diameter) or in deep horizontal tunnels. In a "down-hole shot," the nuclear device is mounted in a cylindrical device canister. Dingnostics, consiatins of detectors at the ends of collimaled lines of sight that view the device, are installed in a diagnowics canister mounted above the device canister. Coaxial and fiber optic cables connect the detectors to recording trailers bocked at the ground eurface. After the device and diagnowic caniaters and the attached cables have been lowered to the bottom of the hole, the hole is filled with and, gravel, and epoxy pluge to prevent radioactive gases generaled by the blest from reaching the ground surface. Of course, no waces is pomible ostee the caniaters have been lowered. The canisters and cables must be designed to withstand the abration and impact of and, gravel, and rocks plummeting several hundred metres down the hole, temperatures up to $110^{\circ} \mathrm{F}$, and moisture. When the device is detonaled acveril days bater, the diegnoatic must survive an onshught of intense radiation, record the decired data, and trananit it "uphole" to the recording syatem before it is deatroyed.

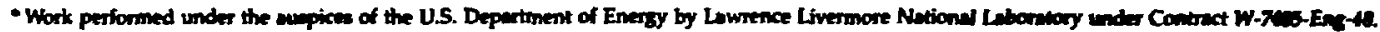

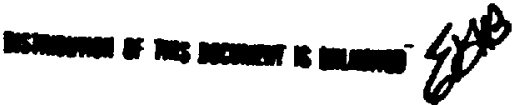




\section{5}

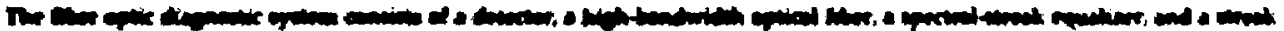

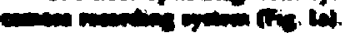

D.

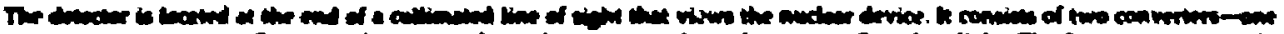

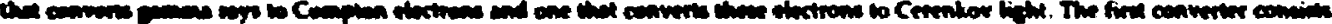

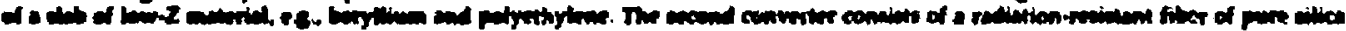

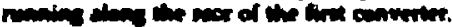

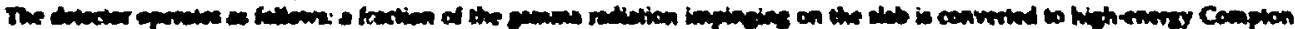

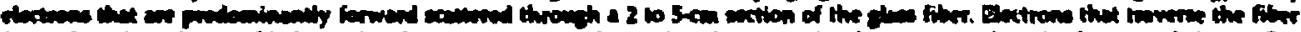

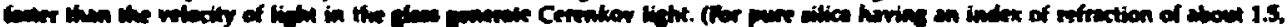

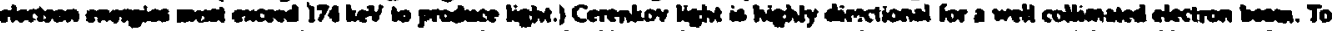

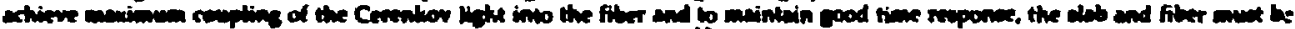

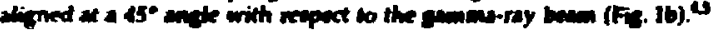

1.)

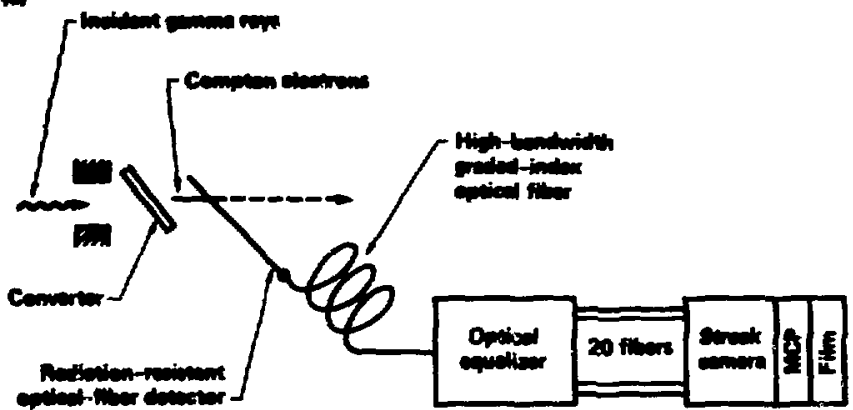

at

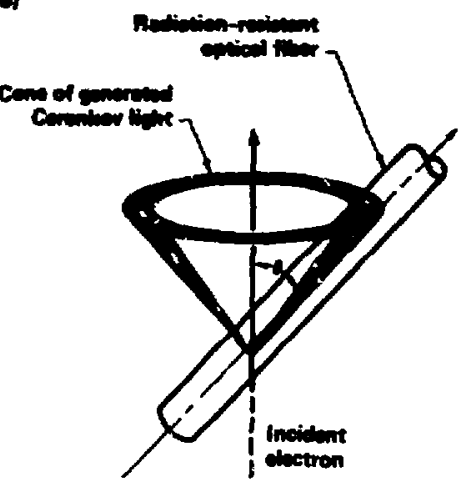

Fieure 1. (a) The fiber optic diagnontic syatem, conainting of a detector, a high-bandwidth optical fiber, a spectral-etreak equalizer, and a wreak camera recording syatem. Camma rays from a nuclear wource are converted into high-energy Compton electrons that generate litht in a sadiation-retiutant optical fiber. The light is tranamitted through a long graded-jndex fiber to the spectral-atreak equalizer, which procences the light for recording by the streak camera. (b) The cone of Cerenkov light generated when Compton electrons traverse the fiber fenter than the velocity of light in the fiber. To tranamit the maximum amount of light up the fiber, the angle 1 munt be about $45^{\circ}$.

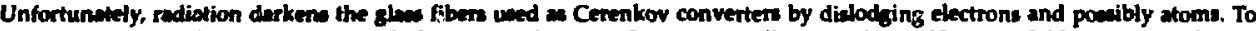
avoid attenustion caund by this radietion darkening, we have und the most radiation-resietant fibers available: pletic-clad silica

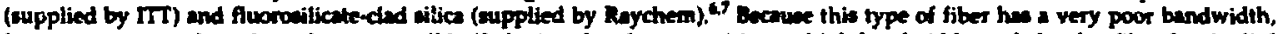
however, we mus keep it as thort as poeible $(3-1 \mathrm{~m})$ and muke a tranation to high-bandwidth graded-index fiber for the link uphole.

To reduce rediation darkening further, we used a low- $Z$ manerial as the gamma ny-to-Compton eletton converter insted of bran, which was und previounly. This subatitution increaned the effective yield of Cerenkov light by 30\%."

Stadies have ales shown that radiation-induced durkening $\mathrm{cm}$ be lenened by maintaining the fiber at an elevated ternperature."

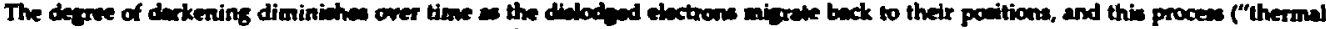

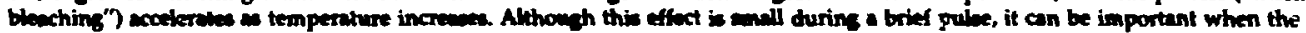

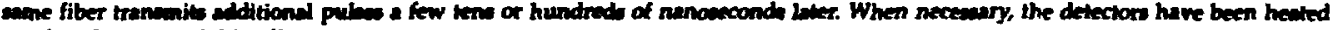
to the advantere of this effect.

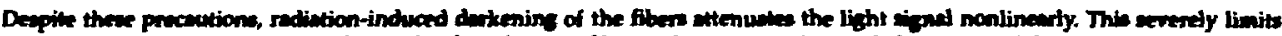

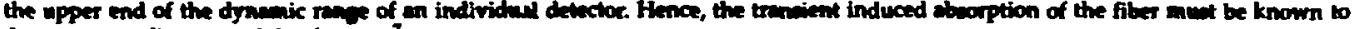

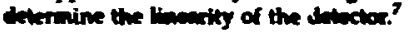




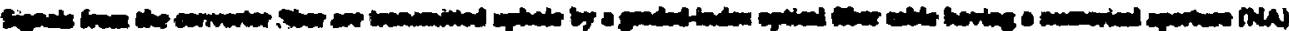

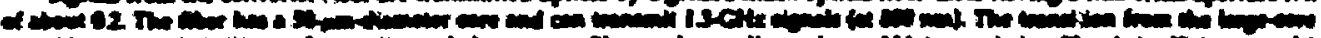

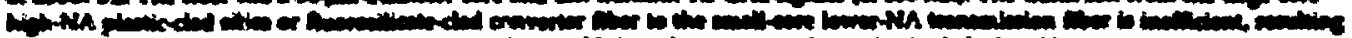

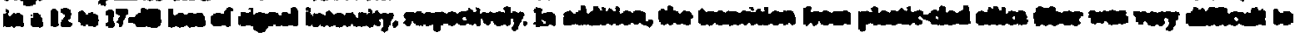
and.

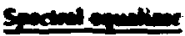

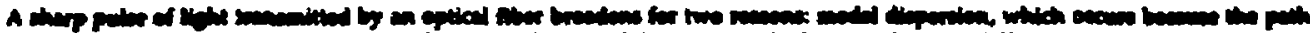

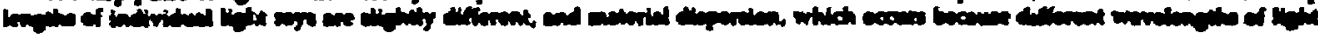

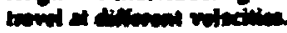

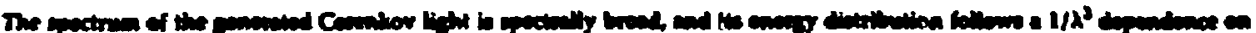

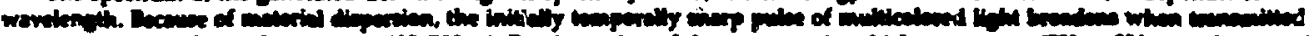

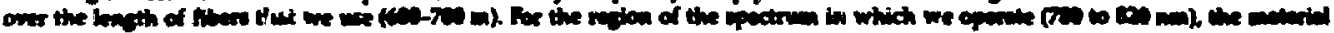

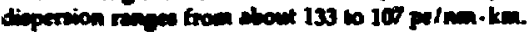

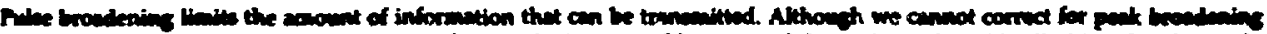

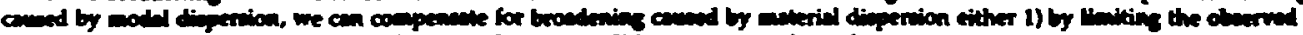

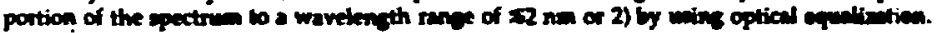

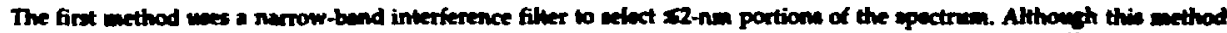

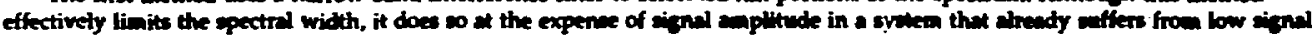
levets resulting from the incficient procewes of Compton and Cenenkov coaverion.

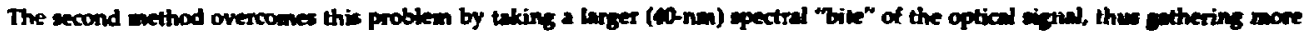
light. A 40-nm portion of the spectrally wide signal is extracted and compresed as follown (ln this explanution, we treme the path of a signal produced by the source at a given inetant in time.) Light from the fiber is foctecd onio a refiection preting that dieperves the light into its spectral components. The spectrum is focuend onto a lineer fiber array arranged so thet each fiber ceiches a difienent 2-nm band of the spectrun and cut to different lengths so that (earty) boner-wavelength light pulese travel farther than the (lebe) shorter-wavelength pulaes (Fig. 2).

The relative lengths of the fibers can be adjuled woconding to the requiremento of the reconding aymean. If a phowomultiptier

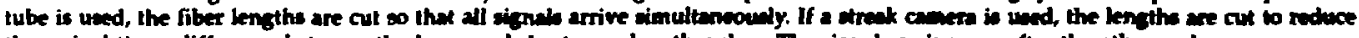
the arrival-times difference between the long- and short-wavelength pulses. The aignals arrive one after the other and are superimposed by the streak camera.

\section{Streak camera}

The streak camera remembles ihe relected 40-nm portion of the dieperaed spectrum a follown: the fiber array in aligned parallel

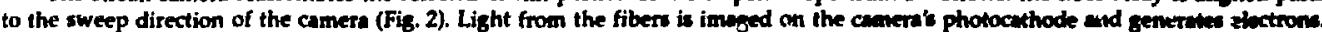
Sweep plates in the camera deflect the etream of electrons acrow the output phoephor to which the film is exponed. If no definction voltage were applied to the sweep plates, the electrons generated at the photocathode would be focuned on the ontput phomphor in the sume pattern as the fiber array. With the constantly increacing sweep voltage applied, however, the electrons correpponding to each fiber can be made to strike the same point on the phosphor. That is, because the sweep voltege increanen with time, ebetrons generated by shorter-wavelength light (which arrives lw) we a stronger deflection field then etectrons generwed by longerwavelength light (which arrives firs). When the camera's sweep upeed is carefully coordinated with the apeed of signals throwin the fibers in the array, the camera superimpones the signals at the same point on the phospor.

As explained above, this path is taken by a signal generated at one inctant in time at the cource. A complete aignal oppona as a streak on the film. To convert the streak to an intensity-ve-time curve, the film is read using a microdensitometer, and the desta are processed by computer.

By selecting only a narrow 2-nm bund of wavelengths, eaci fiber in the array provides an ontput signel that in a mone faithfil representation of the input signal from the downhole light ecurce, but its intensity is weak. However, the streak equaliantion technique combines the outputs of all 20 fibers on the wene spot of the treak canere's phosphor.

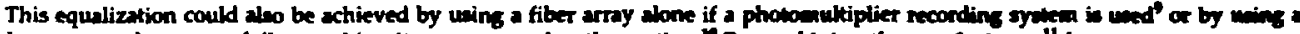

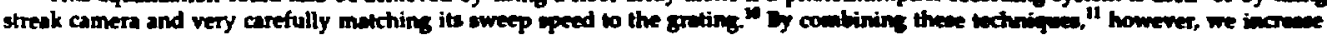

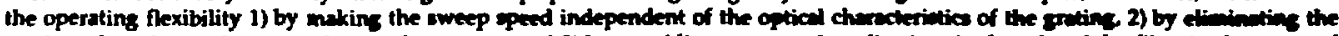
need to place the grating very clowe to the camern, and 3) by providing a wom, by ativeting the lengths of the firer in the arres, of

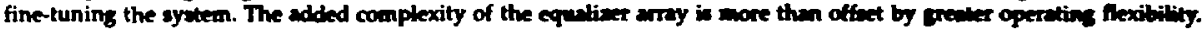




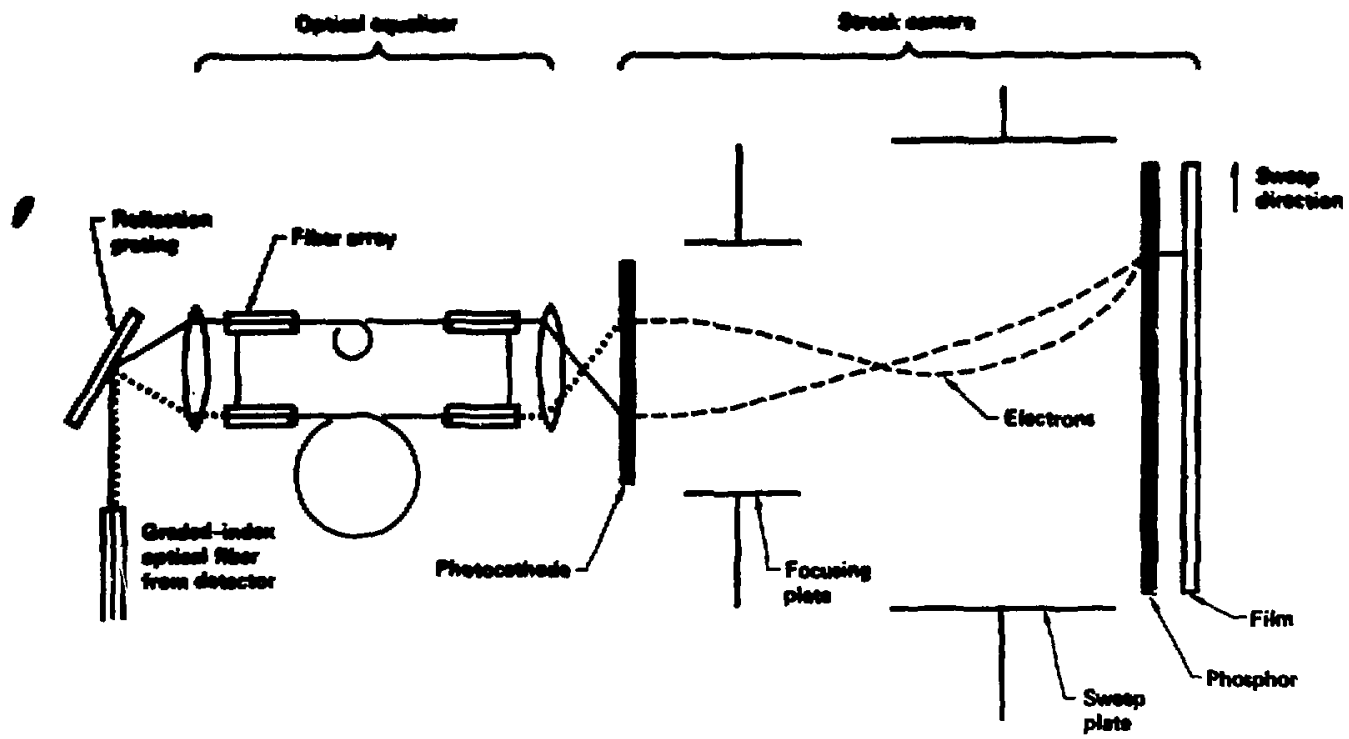

Figure 2. Operation of the spectral-wiresk equalizer and streak camera reconding sysiem. Light from the fiber is focused onto a reflection grating (kens not shown) lhat dieperses the light into its spectral components. The spectrum is focused onto a linear array of 20 fibers arranged so that each fiber catches a different adjecent 2-nm band of the spectrum. The fiber lengths have been adjusted to reduce the arrival-times difference between the long- and thort-wavelength pulses. Thus, the faster lower-frequency light pulses (aclid line) travel farther than slower higher-frequency pulses (dotted line). The signals arrive one after the other at the end of the fiber array where they are focused onto the camera's photocathode and generate electrons. Sweep plates, to which a constantly increasing sweep voltage is applind, however, deflect the electront wo that they strike the same point on the phosphor. The phosphor emits light that is recorded on the fiJm.

We built our streak camera using streak tubes manufactured by RCA, $40 \mathrm{~mm}$ microchannel plate intensifiers from ITT, and cameta electronics and housing made at LLNL. We selected the streak tubes that had the best photocathode efficiency in the Jegion of 780-520 nm. Signals are recorded on Kodak Royal-X pan film. To date, we have uaed two different sweep speeds-60 ma and $15 \mathrm{~ns}$.

We betieve that ous present streak camera syatem offers several advantages oves high-ypeed photomultiplier tubes and cacilloscopes. It can record signals having riactimes of about 100 ps. It can accept many channels. Although the preceding explanation detcribes the process of recording data from a single channel, we have typically used atreak cameras to record 25 channels of information sinultaneoudy (Fig. 3). Because the dats are recorded by one cumera on the same piece of film, interchannel timing and relative anplitude can be more preciely determined. It can replare up to $\$ 0$ axilloceppes, which allows corresponding reductions in cons.

\section{Calibration}

The procew of lowering the device and dingnostic-caniuter membly downhole and filling the hote plua the high downhole temperatures can significently alter the fiber lengths, and thus fiber transit times, by cable stretching and thermal expanaion. ${ }^{12}$

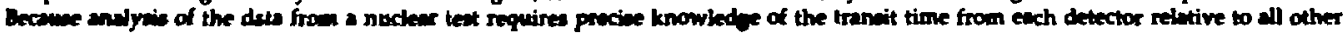

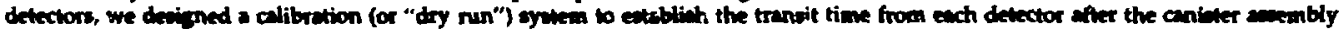

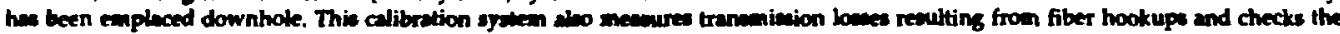
bytem's inicgrity.

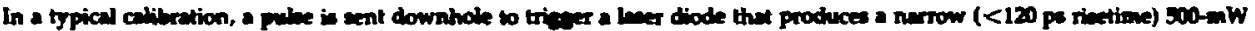

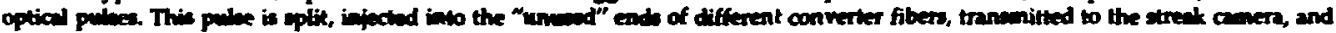

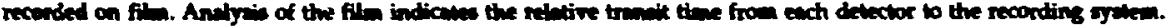

\section{Srever perforence}

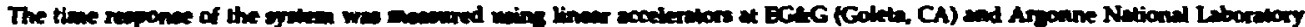

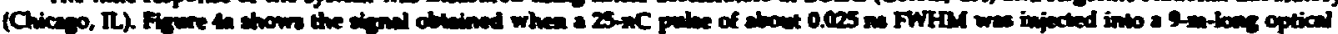




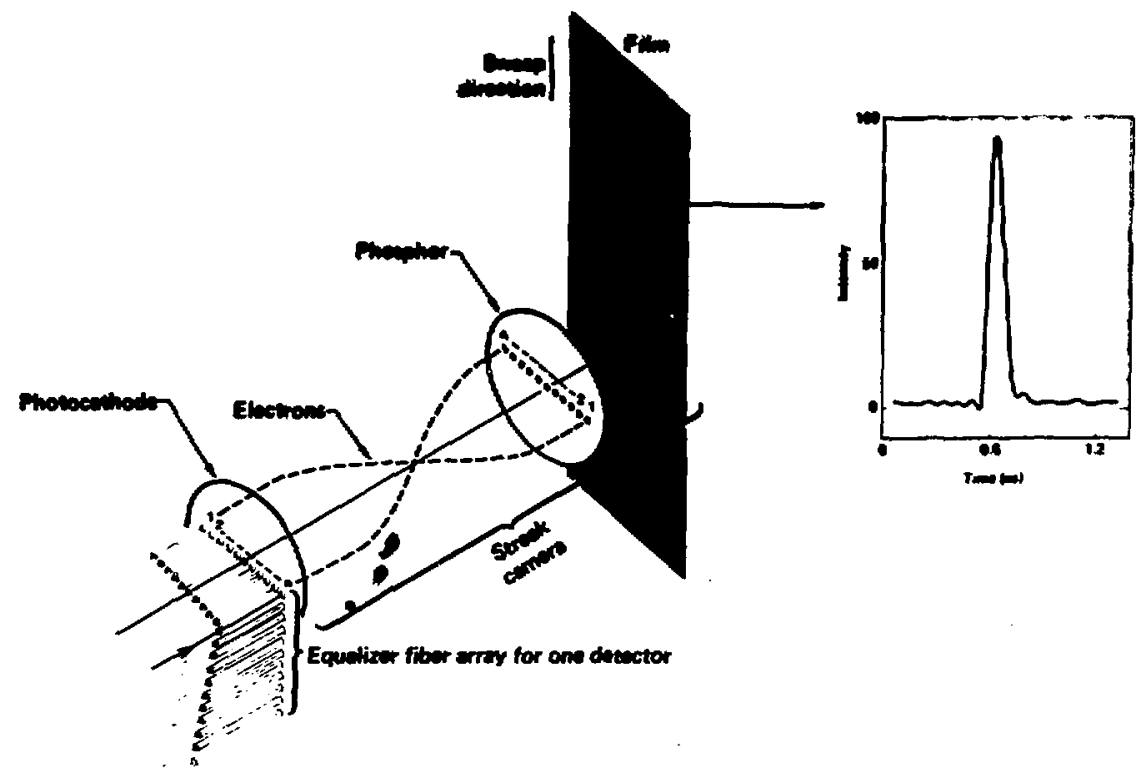

Figure 3. Configuration of a sireak camera system that can record multiple optical fiber channels. The vertical fiber arrays of the optical exualizer for each channel are positioned in front of the photocathode. As the elextrons move towand the phosphor, they are not only deflected vertically by sweep plates (not shown) but also focused onto the phosphor, which is intentified to expose the film. A complete signal appears as a streak on the film. The film is read using a microdensitometer, and the data are proceseed by computer to produce an intensily-vs-time curve.
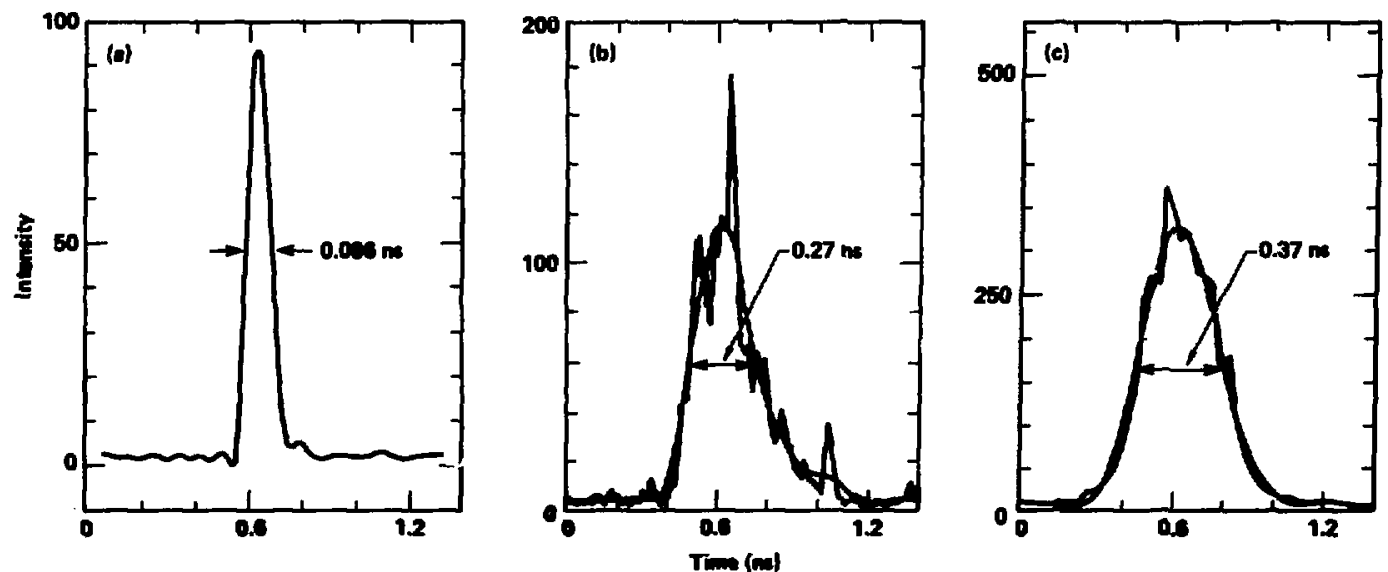

Figure 4. Time response of the system mewured ueing a $25-\mathrm{nC}$ pulse of about $0.025 \mathrm{~ms}$ FWHM produced by a linear accelerator. (a) Signal obtained when the puloe was injected into a $9-m-f o n s$ optical fiber and reconded by the atreak camera using a $15-n$ smeep

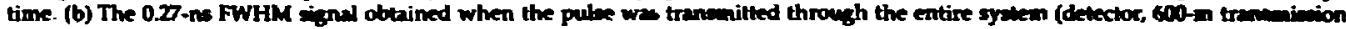
fiber, equalizer, and streak camera) uing a 15-ru sweep kength and (c) the 0.37-r. FWHM peak obtained ming a ca-re aweep. 


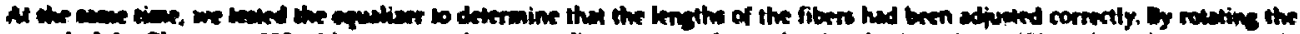

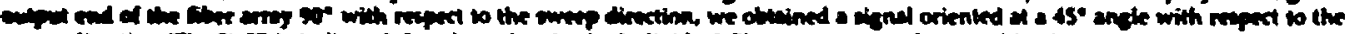

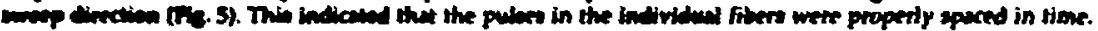

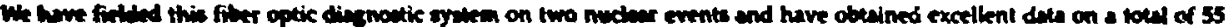

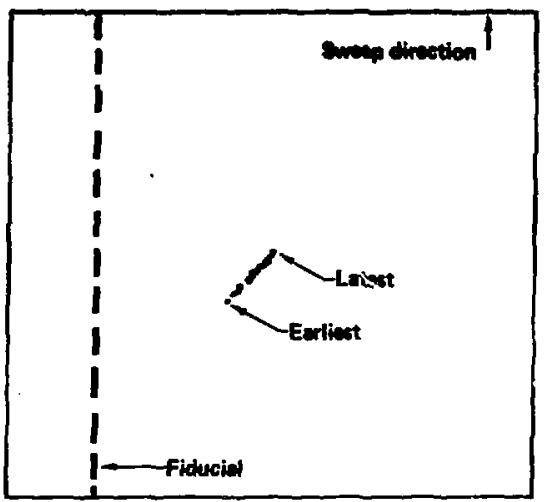

Figure 5. Relative arrival times of light pulses at the output end of the optical equalizer fiber array. The signal oriented at a $45^{\circ}$ angle with respect to the sweep direction was obtained by rotating the fiber array $90^{\circ}$ with respect to the sweep direction. The signal shown here indicates that the pubses in the individual fibers were properly spaced in tinne.

\section{Projected improvements}

We foresee significant improvements in the accuracy, sensitivity, and dynamic range of this system when certain technological advances are achieved. Two of these improvements would extend the lower limit of the system:

- A streak camera having increased quantum efficiency (QE). The QE of the present system is $0.2 \%$ at $800 \mathrm{~nm}$. An increase to $3-4 \%$ would give a ten-fold increase in sensitivity.

- A high-bandwidth graded-index fiber having a larger-diameter core (up to $100 \mu \mathrm{m}$ ). Such a fiber would reduce the mismatch at the junction with the radiation-resistant convert fiber and thus decrease the signal loss at this junction.

A third improvement would extend the upper limit of the system:

- A glass fiber having increased resistance to radiation-induced darkening. Such a fiber would allow observation of more intense beams. The development of better converter materials and changes in the detector geometry are being investigated.

\section{References}

1. Nelson, M., Davies, T. J., and Morton, J. R., Rediation Detection Systems, U.S. Patent 3,984,332 (Oct. 5, 1976).

2. Lyons, P. B., Golsb, J. E., Looney, L. D., Robichaud, R. E., Neloon, M. A., and Davies, T. J., in Proc. Electro-Optics/Laser 77 Conference, 1977 (Industrial and Scientific Conference Management, Inc., Chicago, IL, 1977), p. 545.

3. Ozle, I. W., Lyons, P. B., Looney, L. D., Hockex, L., Nelson, M., Zggarino, P., and Davies, T. J., "Tmprovenents to a HighFrequency Fiber-Optic System for Placun Diegnoetics" in Proc. Sac. Photo-Optical Instrum. Eng., 25ih Technical Symposium, San Diego, 1981 (Society of Photo-Optical Intrumentation Engineers, Bellingham, WA, 1981).

4. Pruett, 8. L., Peterion, R. T., Smith, D. E, Looney, L. D., and Shelton, R. A., "Gamma Ray to Cerenkov Light Efficiency for Pure Silica-Core Optival Fibers," This Proceedings.

5. Lyons, P. B., Kelly, R. E, and Looney, L. D., Short-Term Rediation Effects in Optical Fibers, Los Alamos National Laboratory, Los Alamos, NM, private cummunication (Narch 1960). 


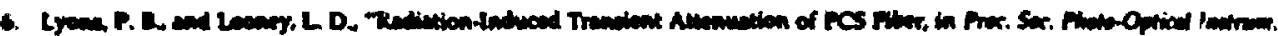

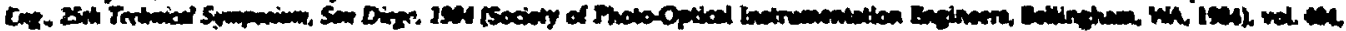
P.

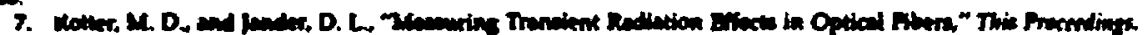

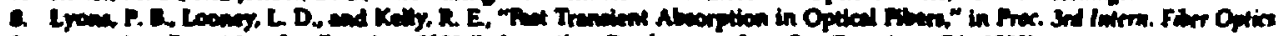

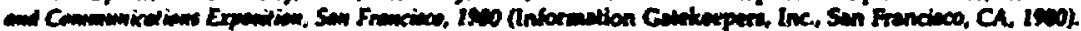

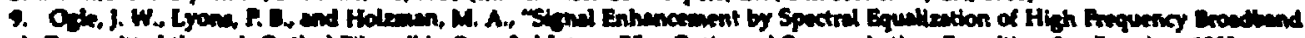

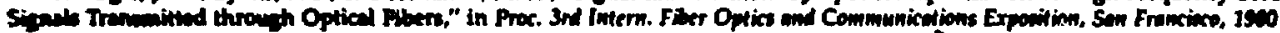

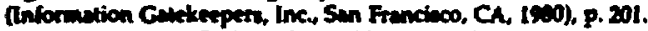

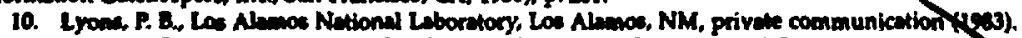

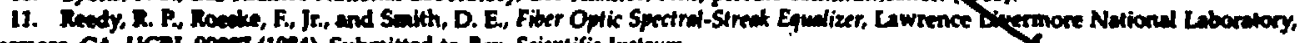
Liwermore, CA, UCRLroour (1504). Subnitted to Rev. Scientific Indirum.

12. Opje, J. W., Looney, L. D., Fetercon, R. T., Seniley, V., Perranelni, M., Whitaker, D., Nelson, L., Pope, E., Woo, L, Schultz, K, Romero, V. Swanic, A., Coucher, A. F., and Dye, N. H., "Characterization of Fiber Optic Cables under Lange Teriale Loads," This Pracentinge 